\title{
RANCANG BANGUN APLIKASI PENGGAJIAN DAN PRESENSI PEGAWAI PADA PT. PUSAKA BUNDA
}

\author{
Ahmad Fahri \\ Teknik Informatika, Fakultas Teknik dan Ilmu Komputer, Universitas Indraprasta PGRI Jakarta \\ Jalan Raya Tengah No 80, Kelurahan Gedong, Pasar Rebo, Jakarta Timur \\ ahmadfahri285@gmail.com
}

\begin{abstract}
ABSTRAK
PT. Pusaka Bunda adalah sebuah perusahaan yang bergerak dibidang kontraktor yang sudah sangat berpengalaman di Indonesia dengan memiliki tenaga pekerja yang profesional. Sampai saat ini pengumpulan data pegawai masih belum terkumpul secara terstruktur dan terintegrasi antara pengolahan presensi dan penggajian. Proses pendataan dan pengiputan data karena tidak akuratnya sehingga membutuhkan waktu yang lama dan penggajian dan presensi pegawai pada PT. Pusaka Bunda masih menggunakan sistem konvensional belum menggunakan sistem komputerisasi. Tujuan merancang suatu sistem informasi penggajian dan presensi ini dengan tujuan untuk memudahkan admin dalam memproses pengolahan data yang ada saat ini. Perangkat aplikasi yang telah dibuat dengan bahasa pemrograman Java NetBeans 8.0.2 dan penyimpanan data pada database MySQL dapat memberikan kelancaran dalam proses menginput dan penyimpanan data-data serta laporan-laporan yang diberikan kepada pimpinan perusahaan. Dengan menggunakan metode pengembangan sistem yaitu Waterfall dalam penelitian ini adalah dengan tahapan-tahapan seperti rekayasa sistem, analisis, desain, coding, testing, dan maintenance. Hasil dari penelitian ini merancang suatu aplikasi yang dapat memudahkan dalam proses penginputan, pencarian data serta pembuatan laporan perbulannya lebih baik dan akurat.
\end{abstract}

Kata Kunci: Aplikasi, Penggajian, Presensi, Pegawai

ABSTRACT

PT. Pusaka Bunda is a company engaged in contractors who are very experienced in Indonesia by having professional workers. Until now, employee data collection has not been collected in a structured and integrated manner between attendance and payroll processing. The process of data collection and data entry because it is not accurate so it takes a long time and the payroll and attendance of employees at PT. Pusaka Bunda still uses a conventional system but does not use a computerized system. The purpose of designing a payroll and attendance information system is to make it easier for admins to process the current data processing. Application tools that have been created using the Java NetBeans 8.0.2 programming language and data storage in the MySQL database can provide smooth processing of input and storage of data and reports provided to company leaders. By using the system development method, namely Waterfall, in this research, the stages are systems engineering, analysis, design, coding, testing, and maintenance. The results of this study design an application that can facilitate the process of inputting, searching for data and making monthly reports better and more accurate.

Key Word: Application, Payroll, Attendance, Employee

\section{PENDAHULUAN}

Sistem informasi merupakan salah satu alat bantu penunjang pekerjaan dalam organisasi baik profit maupun non profit (Mayasari, 2015). Informasi dibutuhkan sebagai salah satu sumber daya vital yang akan menjadi perhatian utama perusahaan dalam menjalankan organisasi bisnis mereka. Selain itu, sistem informasi yang digunakan di sebuah perusahaan merupakan sebuah alat ukur dari tingkat prestasi atau kinerja dari perusahaan itu sendiri. Semua bisnis yang berjalan dengan baik tentunya memiliki sumber informasi serta pengolahan informasi yang berkualitas pula. Sebuah sistem informasi yang baik dapat bekerja secara langsung, terhubung, dan memberikan informasi yang lengkap dari berbagai fungsi maupun proses bisnis yang ada di dalam perusahaan. Sistem informasi berbasis komputer merupakan suatu alat yang dapat menunjang tingkat kelancaran dalam melaksanakan kegiatankegiatan perusahaan (Septiani, Goni, \& Sayfulloh, 2017).

Sistem informasi yang diperlukan oleh perusahaan antara lain sistem informasi penggajian dan 
presensi. Sistem infomasi penggajian merupakan hal yang sangat pokok pada kegiatan finansial sebuah instansi, karena hal tersebut sangat berpengaruh terhadap kinerja para pegawai dan memudahkan admin dalam mengolah data pegawai. Dengan sistem informasi penggajian akan membantu dalam proses pengelolaan gaji pegawai sehingga admin memperoleh kemudahan dalam mengoperasikan sistem (Suyanti, 2017).

PT. Pusaka Bunda adalah sebuah perusahaan yang bergerak dibidang kontraktor yang sudah sangat berpengalaman di Indonesia dengan memiliki tenaga pekerja yang profesional. Sampai saat ini pengumpulan data pegawai masih belum terkumpul secara terstruktur dan terintegrasi antara pengolahan presensi dan penggajian (Tani, Bagre, \& Adam, 2018). Artinya kedua kegiatan tersebut masih dilakukan secara terpisah. Proses pendataan pegawai tiap bulan masih dicatat dalam sebuah buku khusus, dan untuk menyerahkan bukti laporan gaji masih bersifat konvensional. Masalah yang timbul adalah ketidak konsistenan data yang dapat menyebabkan kerangkapan data, apabila dalam pencarian data membutuhkan waktu yang sangat lama karena masih menggunakan sistem yang konvensional,dan keamanan data pun masih kurang terjamin (Subhi \& Irfansyah, 2020).

Dengan permasalahan tersebut, perlu ada nya suatu sistem yang terkomputerisasi dalam penyelesaiannya. Sistem adalah sekelompok unsur yang erat hubungannya satu dengan yang lain, yang berfungsi bersama-sama untuk mencapai tujuan (Sutabri, 2012). Sistem merupakan suatu kumpulan dari komponenkomponen yang membentuk satu kesatuan (Tyoso, 2016). Pembangunan sistem adalah sekumpulan aktivitas yang menggambarkan secara rinci bagaimana sistem akan berjalan. Hal itu bertujuan untuk menghasilkan produk perangkat lunak yang sesuai dengan kebutuhan user (Satzinger, J. W., Jackson, R. B., Burd, n.d.).

Diharapkan dengan adanya suatu sistem informasi dapat menangani permasalahan yang ada di perusahaan tersebut. Sistem adalah setiap sesuatu terdiri dari obyek-obyek, atau unsur-unsur, atau komponen-komponen yang bertata kaitan dan bertata hubungan satu sama lain, sedemikian rupa sehingga unsur-unsur tersebut merupakan satu kesatuan pemrosesan atau pengolahan yang tertentu. (Prasojo, 2011)

Aplikasi ini dapat memudahkan pekerjaan Admin dalam melaksanakan pembuatan laporan dan dapat memudahkan perusahaan dalam memproses data pegawai, data presensi, data penggajian dan data bonus pegawai pada PT. Pusaka Bunda.

\section{METODE PENELITIAN}

Peneliti menggunakan metode Research and Development dalam penyelesaian penelitian ini. (Sugiyono, 2016). Dalam pelaksanaan R\&D, ada beberapa metode yang digunakan yaitu metode deskriptif, evaluatif dan eksperimental. Metode penelitian deskriptif digunakan dalam penelitian awal untuk menghimpun data tentang kondisi yang ada yaitu penulis membutuhkan data-data yang dapat menunjang tercipta nya suatu sistem informasi pengolahan data pegawai dan penggajian seperti data pegawai, data jabatan, data presensi, data penggajian dan data bonus pegawai terdahulu yang masih tersimpan secara manual didalam buku besar. Metode evaluatif digunakan untuk mengevaluasi proses ujicoba pengembangan suatu produk, dalam proses ini penulis melakukan ujicoba terhadap suatu sistem yang telah dirancang agar tidak ada terjadi kesalahan dalam proses penginputan data serta pelaporan bulanan kepada pimpinan. Dan metode eksperimen digunakan untuk menguji keampuhan dari produk yang dihasilkan, dalam proses yang terakhir ini perlu dilakukan pengujian akhir yang diharapkan bahwa sistem yang dirancang oleh penulis dapat berjalan dengan baik dan sesuai dengan kebutuhan dan terfokus pada proses pengolahan data penggajian dan presensi pegawai pada PT. Pusaka Bunda (Putra, 2011).

\section{HASIL DAN PEMBAHASAN Analisa Permasalahan}

Pada sistem pengolahan data kepegawaian dan penggajian serta presensi pegawai di PT. Pusaka Bunda ini ternyata mempunyai beberapa kelemahan karena sistem yang digunakan belum sepenuhnya terkomputerisasi.

1. Dalam proses input data pegawai, data presensi, dan penggajian pegawai masih ada yang dilakukan secara konvensional. 
2. Pencarian data pegawai dan data presensi membutuhkan waktu yang lama dan tidak efektif karena sistem yang ada masih manual sehingga jika mencari data yang dibutuhkan, pencarian dilakukan di arsip.

3. Sistem informasi yang belum terkomputerisasi menyebabkan bagian administrasi menjadi terhambat dan kurang efisien.

4. Kurangnya sumber daya manusia yang memahami sistem komputerisasi.

5. Pembuatan laporan, slip gaji, perhitungan penggajian dan bonus Pegawai yang dilakukan secara konvensional memungkinkan terjadinya kesalahan data dan membutuhkan waktu yang lama dalam memperbaikinya.

\section{Alternatif Penyelesaian Masalah}

Untuk mencari solusi dalam permasalahan yang ada maka penulis membuat suatu sistem yang akan membantu dalam menyelesaikan masalah tersebut. Berdasarkan analisis sistem yang sedang berjalan saat ini penulis melihat beberapa kelemahan dan pokok permasalahan yang terdapat pada sistem pengolahan data kepegawaian dan penggajian di atas, maka penulis memberikan saran beberapa alternatif penyelesaian masalah diantaranya:

1. Merancang sistem informasi terkomputerisasi yang dapat membantu dalam proses penginputan data pegawai, data jabatan, data presensi, perhitungan gaji dan bonus pegawai di PT. Pusaka Bunda.

2. Perancangan database untuk sistem sehingga penyimpanan data tidak menggunakan media kertas lagi.

3. Data yang ada disimpan ke hardisk dan membuat backup-an data.

4. Membuat sistem informasi kepegawaian dan penggajian yang mudah dipahami oleh bagian administrasi dan bagian keuangan agar mudah digunakan

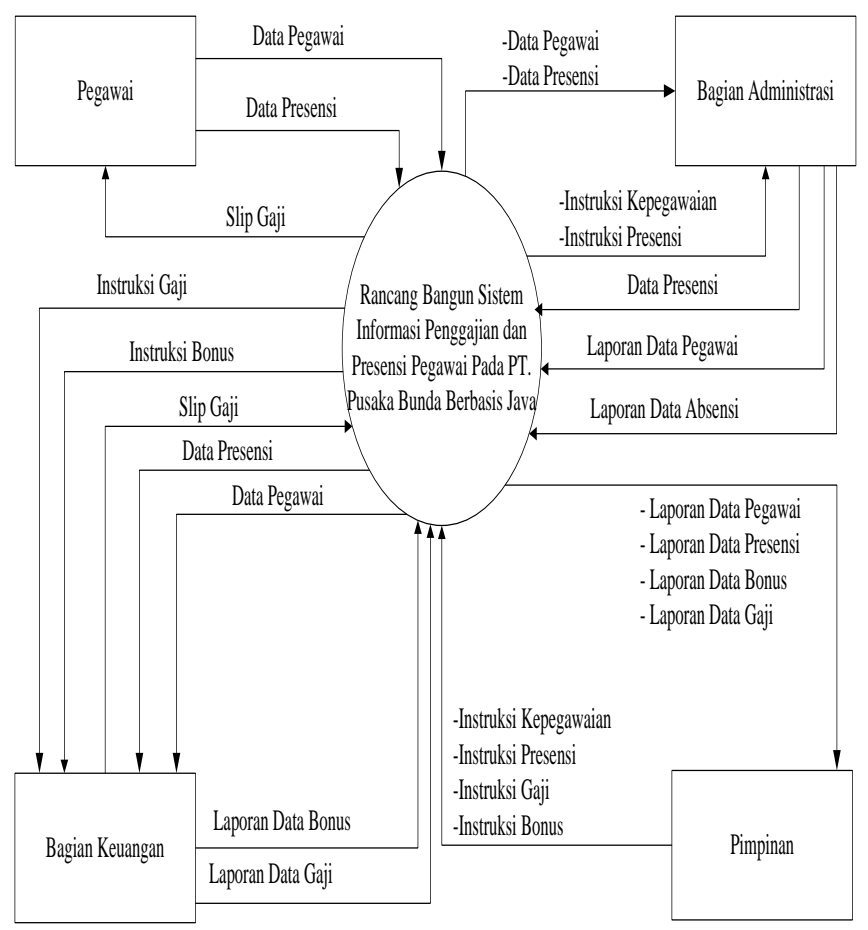

Gambar 1. Diagram Konteks

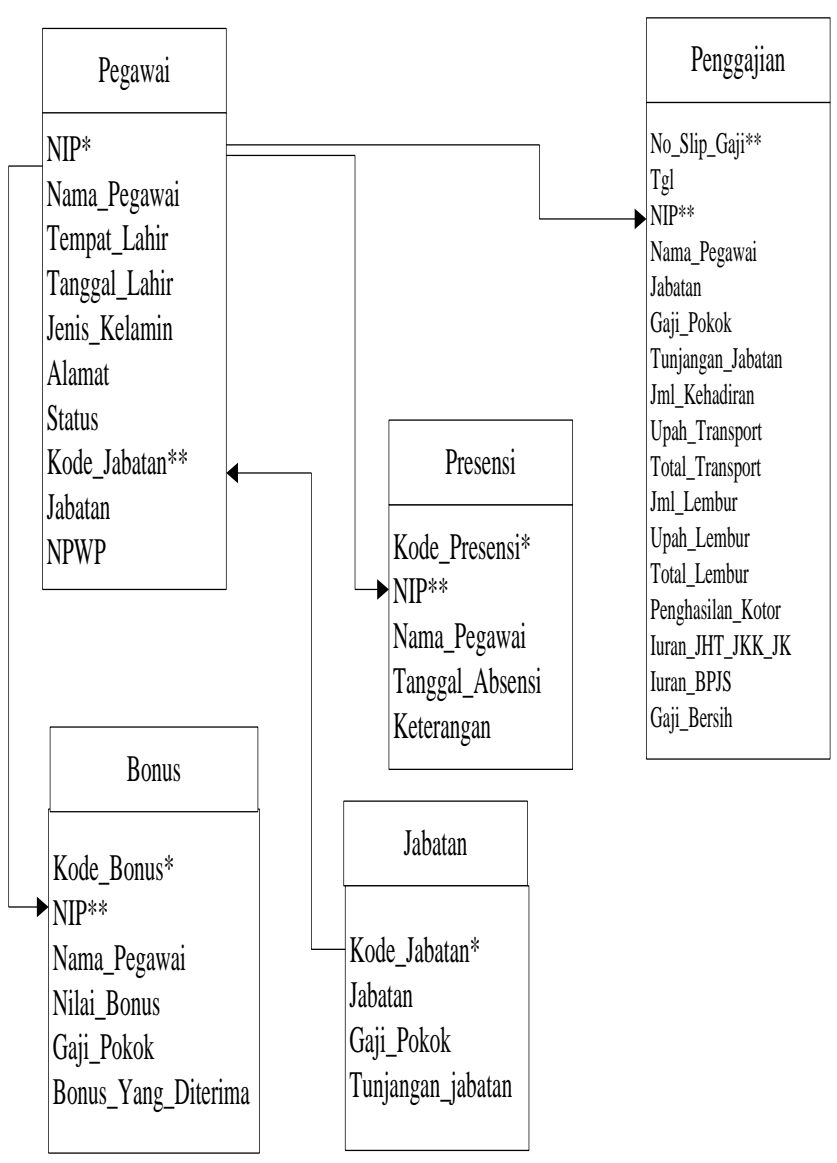

Gambar 2. Normalisasi 


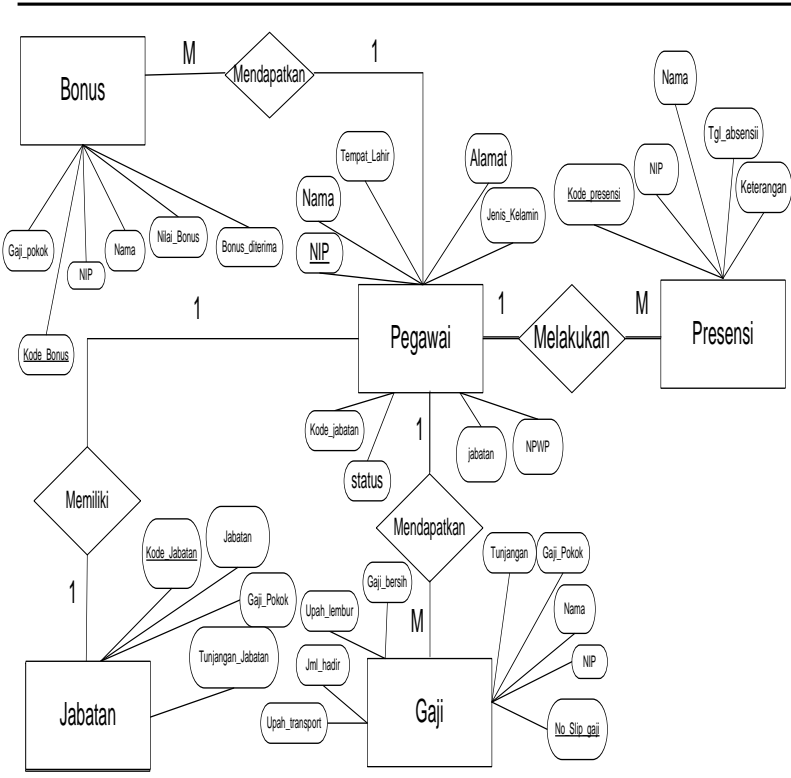

Gambar 3. ERD (Entity Relationship Diagram)

Berikut adalah tampilan layar dan hasil pengujian pada software program yang telah di buat dengan bahasa pemrograman Java.

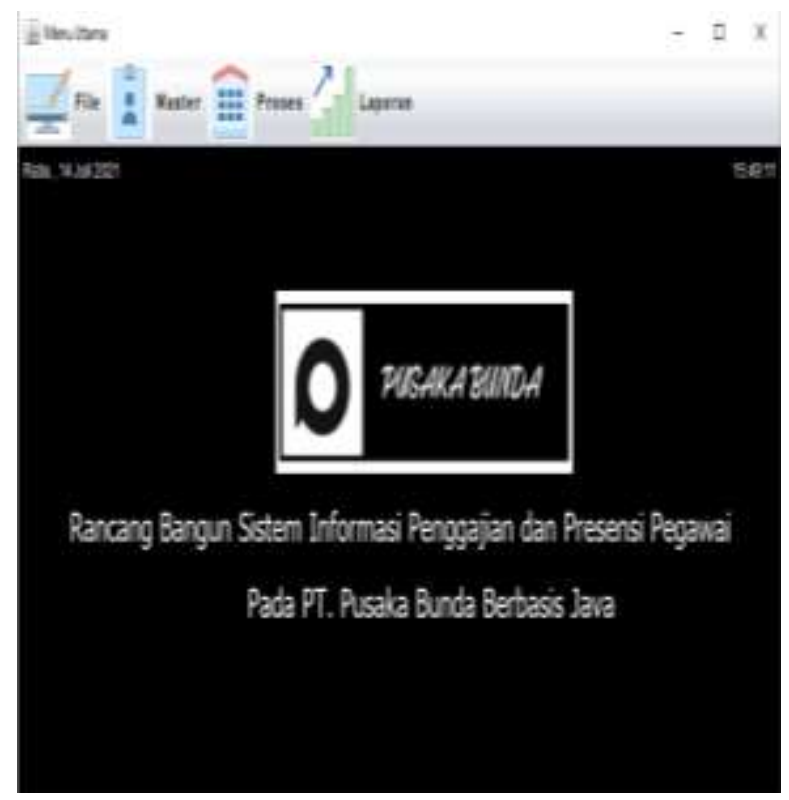

Gambar 4. Form Menu Utama

Layar di atas menampilkan tampilan Menu Utama pada Rancang Bangun Sistem Informasi Penggajian dan Presensi Pegawai Pada PT. Pusaka Bunda Berbasis java. Pada layar utama tersedia menu bar yang terdiri dari master data yang digunakan untuk memasukkan data yang berkaitan dengan data pegawai, data jabatan, data presensi, data penggajian, data bonus dan laporanlaporan serta slip gaji karyawan.

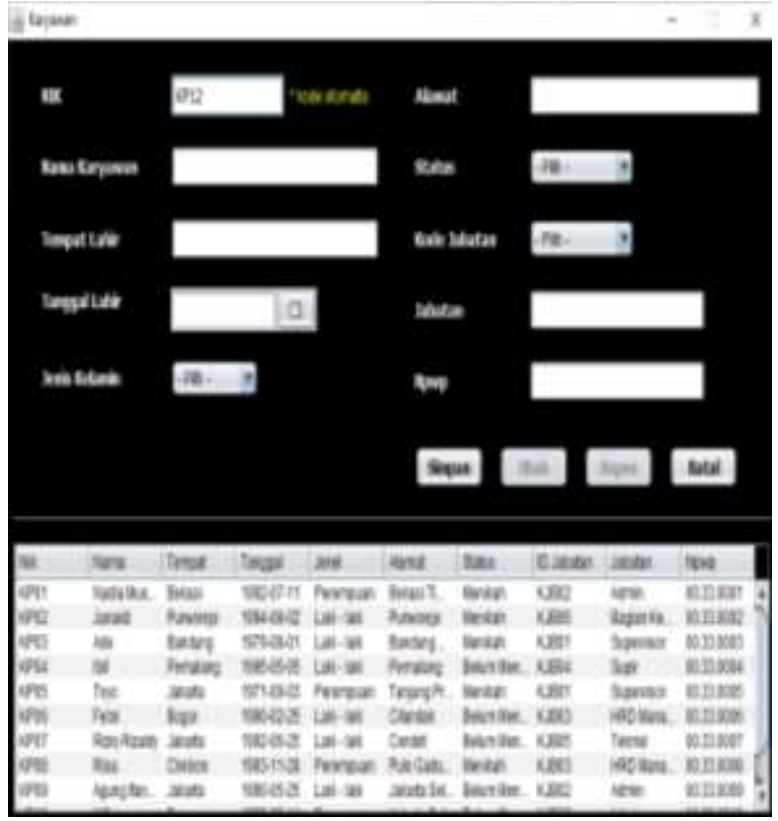

Gambar 5. Form Data Pegawai

Layar di atas menampilkan tampilan form data pegawai. Pada layar form data pegawai untuk meng-input data pegawai yang terdiri dari NIP, Nama Pegawai, Tempat Lahir, Tgl Lahir, Jenis Kelamin, Alamat, Status, Kode Jabatan, NPWP.

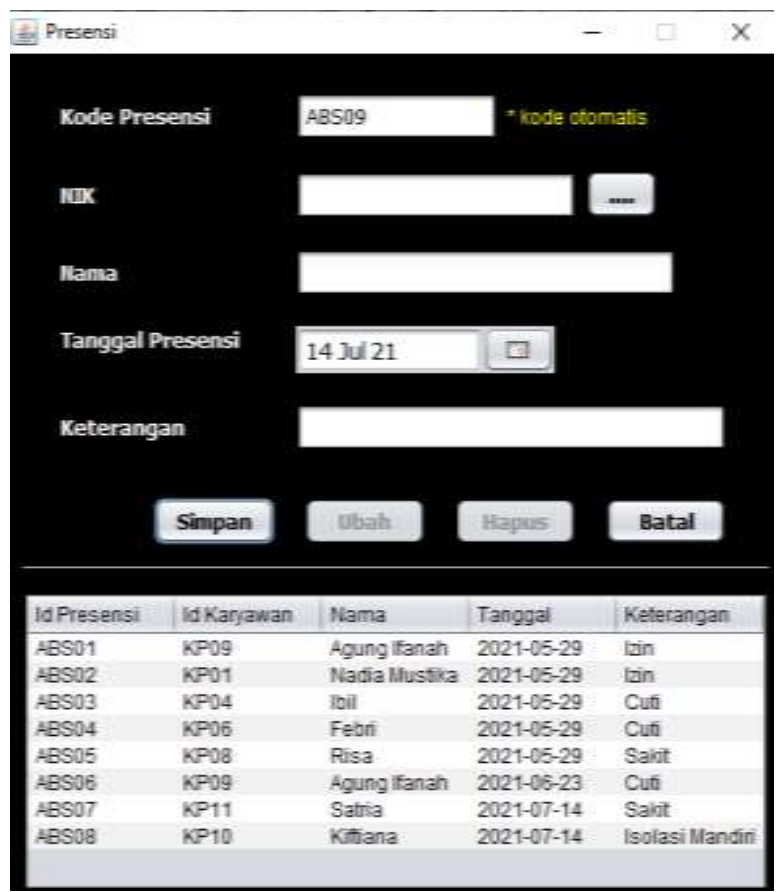

Gambar 6. Form Data Presensi 
Layar di atas menampilkan tampilan form data presensi. Pada layar form data presensi untuk meng-input data presensi yang terdiri dari Kode Presensi, NIP, Nama Pegawai, Tgl Presensi dan Keterangan.

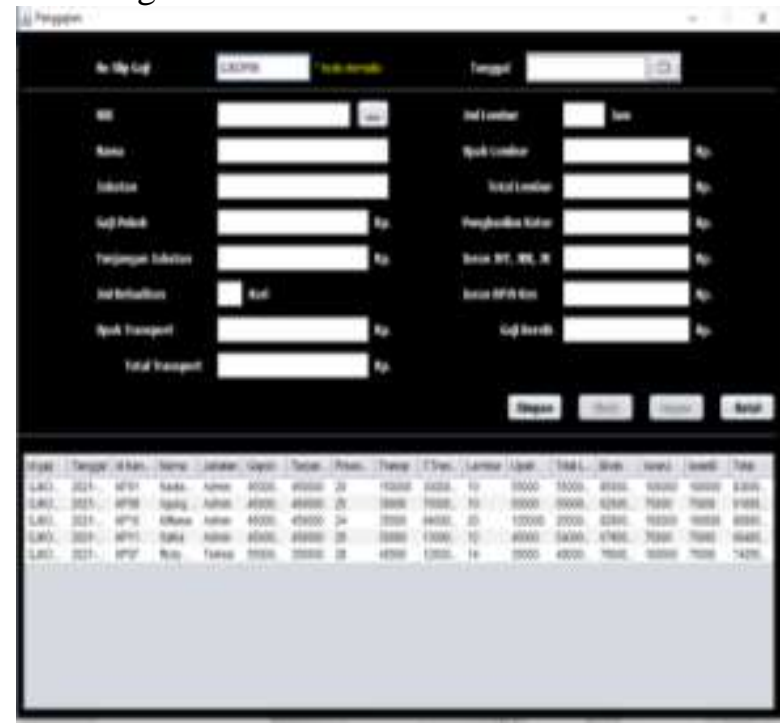

Gambar 7. Data Form Data Penggajian

Layar di atas menampilkan tampilan form data penggajian. Pada layar form data penggajian untuk meng-input data penggajian yang terdiri dari No Slip Gaji, Tgl, NIP, Nama Pegawai, Jabatan, Gaji Pokok, Tunjangan Jabatan, Jumlah Kehadiran, Upah Transport, Total Transport, , Jumlah Lembur, Upah Lembur, Total Lembur, Penghasilan Kotor, Iuran JHT JKK JK, Iuran BPJS Kesehatan dan Gaji Bersih.

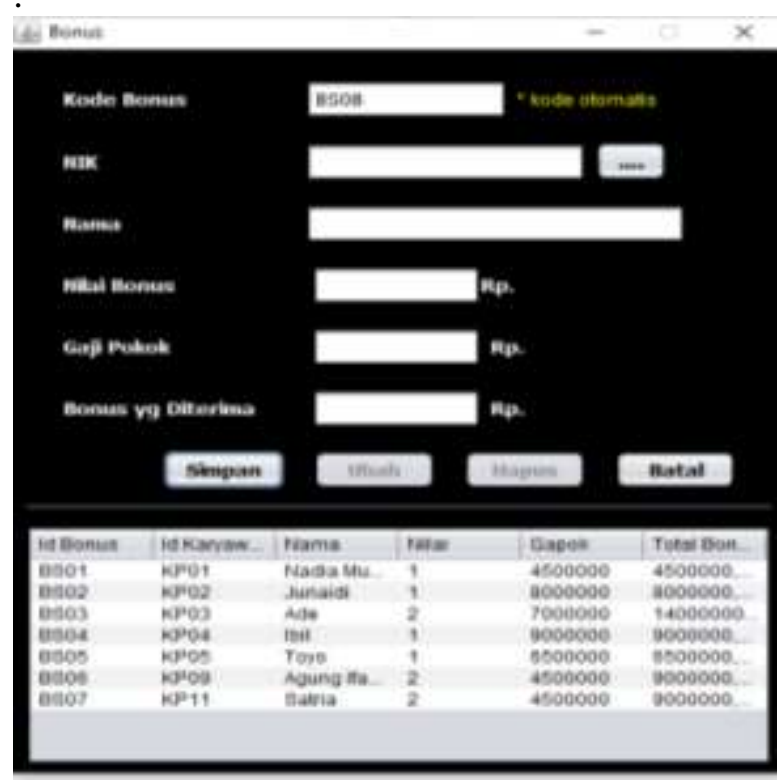

Gambar 8. Form Data Bonus
Layar di atas menampilkan tampilan form data bonus. Pada layar form data bonus untuk menginput data bonus yang terdiri dari Kode Bonus, NIP, Nama Pegawai, Nilai Bonus, Gaji Pokok, dan Bonus yang Diterima.

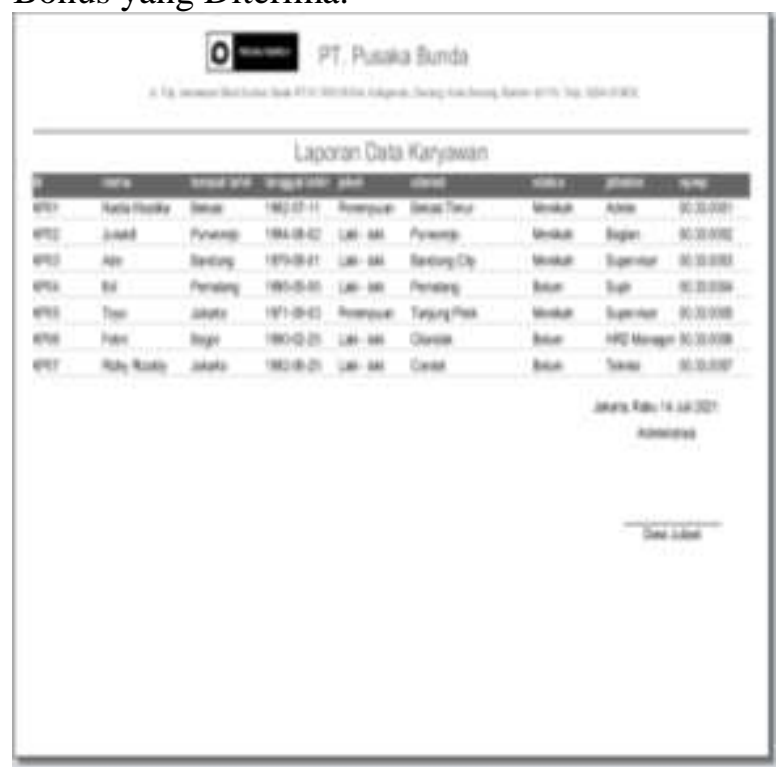

Gambar 9. Laporan Data Pegawai

Layar di atas menampilkan tampilan form laporan data pegawai. Pada layar form data pegawai digunakan untuk mengecek laporan data pegawai terdiri NIP, Nama Pegawai, Tempat Lahir, Tgl Lahir, Jenis Kelamin, Alamat, Status, Kode Jabatan, NPWP.

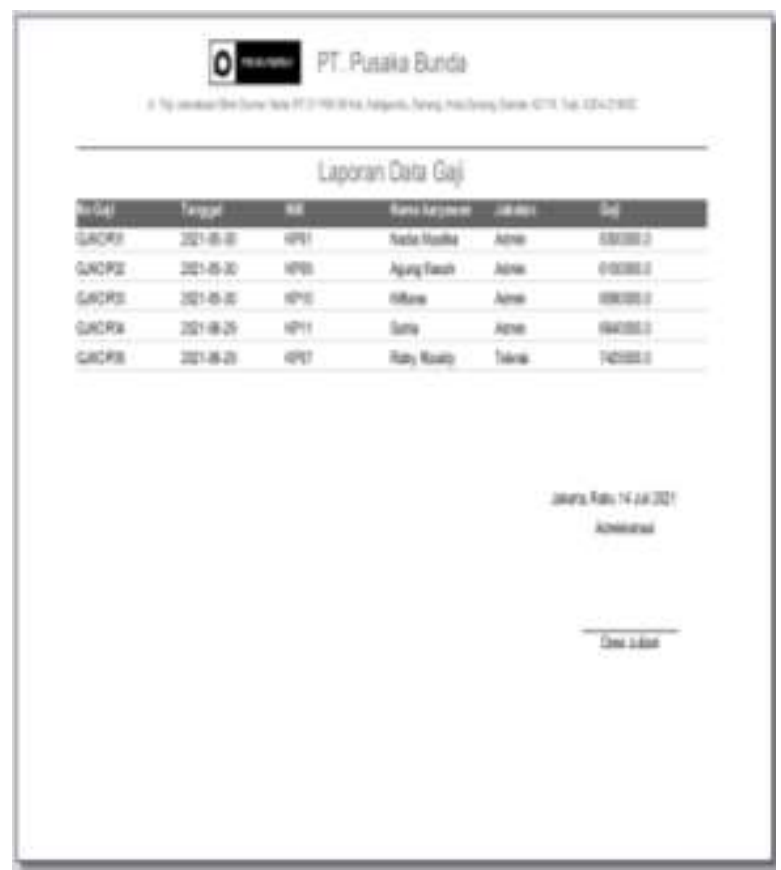

Gambar 10. Laporan Data Penggajian

663 | Rancang Bangun Aplikasi Penggajian dan Presensi Pegawai pada PT. Pusaka Bunda 
Layar di atas menampilkan tampilan form laporan data penggajian. Pada layar form data penggajian digunakan untuk mengecek laporan data penggajian terdiri No Gaji, Tgl, NIP, Nama Pegawai, Jabatan dan Gaji.

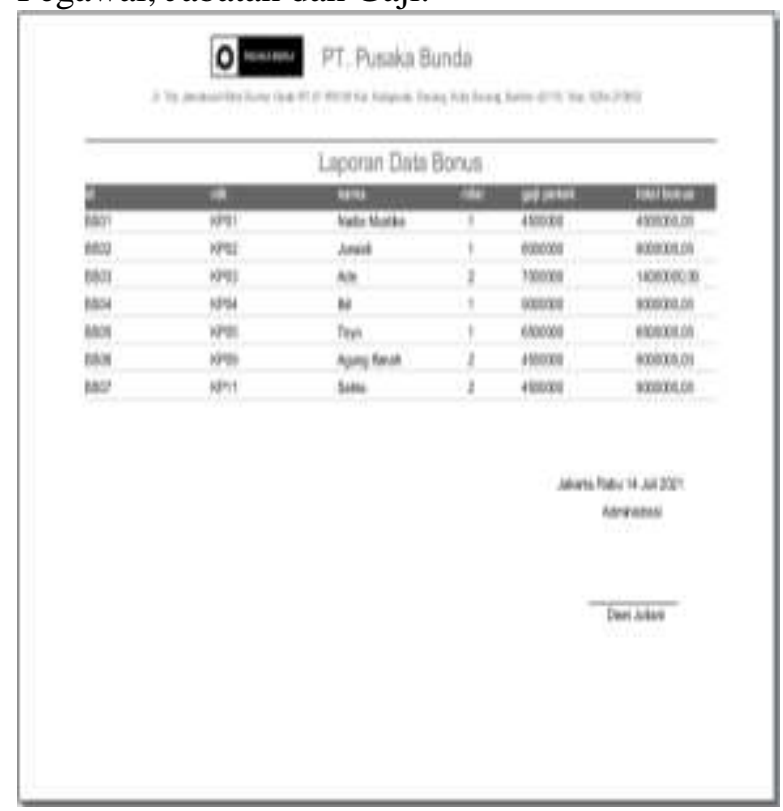

Gambar 11. Laporan Data Bonus Pegawai

Layar di atas menampilkan tampilan form laporan data bonus. Pada layar form data bonus digunakan untuk mengecek laporan data bonus terdiri ID Bonus, NIP, Nama Pegawai dan Bonus yang diterima.

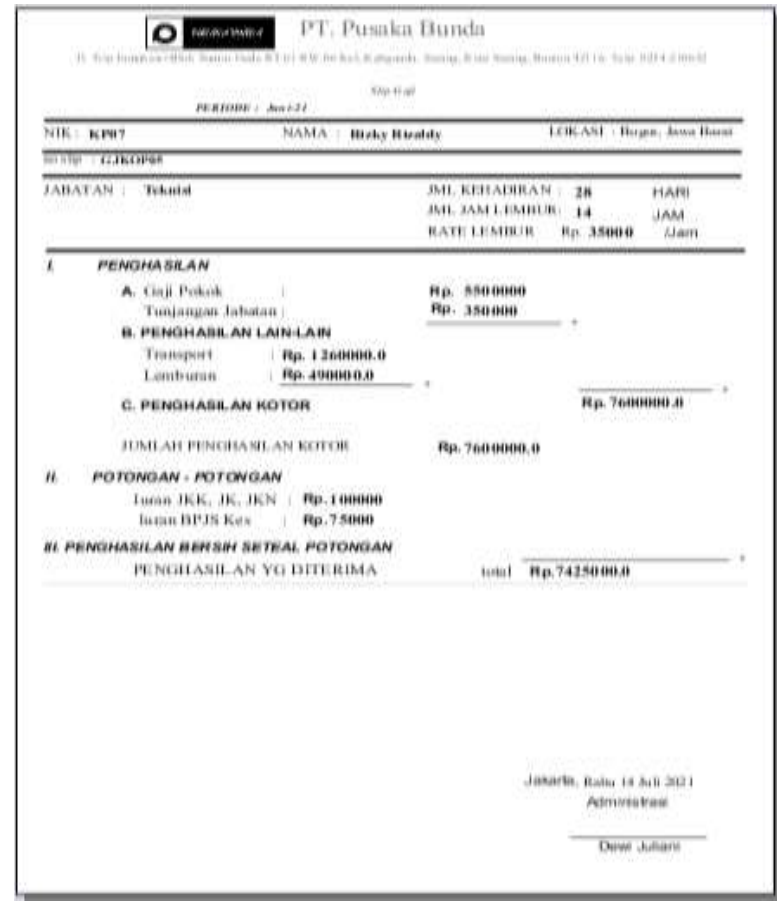

Gambar 12. Slip Gaji Pegawai
Layar di atas menampilkan tampilan form slip gaji pegawai. Pada layar form slip gaji pegawai terdiri dari No Slip Gaji, Tgl, NIP, Nama Pegawai, Jabatan, Gaji Pokok, Tunjangan Jabatan, Jumlah Kehadiran, Upah Transport, Total Transport, Jumlah Lembur, Upah Lembur, Total Lembur, Penghasilan Kotor, Iuran JHT JKK JK, Iuran BPJS Kesehatan dan Gaji Bersih.

\section{SIMPULAN DAN SARAN}

Sistem komputerisasi pengolahan data kepegawaian dan penggajian serta presensi pegawai di PT. Pusaka Bunda, semua kegiatan yang berhubungan dengan pengelolahan data kepegawaian dan penggajian serta presensi pegawai tidak lagi secara konvensional tetapi dengan menggunakan media berupa komputer.

Pada sistem komputerisasi ini, sistem pengolahan data kepegawaian dan penggajian serta presensi pegawai di PT. Pusaka Bunda yang berbasis desktop dapat menangani pekerjaan admin dan bagian keuangan dengan cepat dan akurat serta dapat di up-date dengan mudah dan dengan adanya sistem ini diharapkan akan mempermudah kegiatan atau aktivitas instansi yang memerlukan kecepatan dan ketetapan informasi. Kecepatan dan ketepatan hasil perancangan ini juga membutuhkan partisipasi aktif dari pemakai sistem, terutama kedisiplinan para pelaksanaan yang menangani secara langsung pada sistem yang dirancang.

Sarannya adalah meskipun telah menggunakan sistem yang terkomputerisasi, ketelitian dalam menginput data perlu diperhatikan agar data yang sudah direkam (store) benar-benar merupakan salinan dari data sumber.

\section{DAFTAR PUSTAKA}

Mayasari, M. S. (2015). Analisa Dan Perancangan Aplikasi Sistem Informasi Penggajian Karyawan Pada Pt. Aditya Buana Inter Sungailiat Bangka. Simetris : Jurnal Teknik Mesin, Elektro Dan Ilmu Komputer. https://doi.org/10.24176/simet.v6i2.463

Prasojo, M. (2011). Pengantar Sistem Informasi Manajemen. bandung: CV. Remadja Karya.

Putra, N. (2011). Research and Development, Penelitian dan Pengembangan: Suatu Pengantar. Jakarta: PT Raja Grafindo 
Persada.

Satzinger, J. W., Jackson, R. B., Burd, S. D. (n.d.). System Analysis and Design in A Changing World. USA: Cengage Learning.

Septiani, N. A., Goni, A., \& Sayfulloh, A. (2017). Perancangan Sistem Informasi Penggajian Karyawan Studi Kasus: pada PT. Uniteknindo Inti Sarana Jakarta. Swabumi.

Subhi, I. D., \& Irfansyah, P. (2020). Rancang Bangun Sistem Aplikasi Absensi dan Penilaian Prestasi Kerja pada Remaja Center. Jurnal Riset Dan Aplikasi Mahasiswa Informatika (JRAMI), 1(02), 207-214. https://doi.org/10.30998/jrami.v1i02.245

Sugiyono. (2016). Metode Penelitian Kuantitatif, Kualitatif dan $R \& D$. Bandung: PT Alfabet.

Sutabri, T. (2012). Analisis Sistem Informasi. Yogyakarta: Andi.

Suyanti. (2017). Perancangan Sistem Informasi Penggajian Karyawan Berbasis Desktop Pada Pt. Bs Logistics Batam. Journal of Physical Chemistry B.

Tani, E., Bagre, B., \& Adam, S. (2018). Perancangan Sistem Informasi Kepegawaian PT Sederhana Karya Jaya Berbasis WEB. Seminar Nasional Sistem Informasi Dan Teknologi Informasi 2018 SENSITEK 2018.

Tyoso, J. S. P. (2016). Sistem Informasi Manajemen. Yogyakarta: DeePublish. 